\title{
ARTICLES
}

\section{LEVEL OF STRESS AND COPING AMONG NURSES WORKING AT HIGH RISK}

\section{Ms. Ahila D L*}

*Assistant Professor, Saraswathy College of Nursing, Karode, Thiruvananthapuram, Kerala, India. DOI: http://doi.org/10.47211/tg.2020.v07i03.007

\section{ABSTRACT:}

A study to assess the level of stress and coping among 80 nurses working at high risk areas of selected CSI Hospitals of Kanyakurnari District was done using modified Expanded Nursing Stress Scale devised by American, National Nurses Association and modified Moo's Coping Inventory. 52.5\% (42) of nurses were found to be severely stressed and $40 \%$ (32) nurses were found to be moderately stressed. Only $3.75 \%$ (3) of nurses were having effective coping skills. The association between stress and selected demographic variables like Age, year of experience, type of wards and marital status was found to be significant with $=18.70 ; 20.23 ; 11.27 ; 10.04$ at $(p<0.05)$ level. The association between coping and selected demographic variables like age, year of experience and marital status was found to be significant, $-14.55 ; 15.54 ; 6,54$ at $(p<0.05)$ level.

Key Words: Stress coping, high risk area, selected hospital.

\section{ABOUT AUTHOR:}

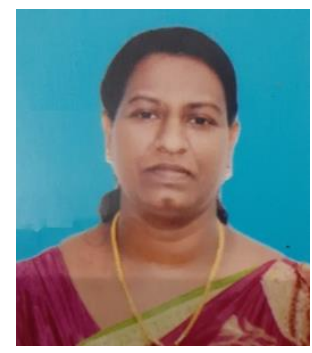

Author Ms. Ahila D L is Assistant Professor in Saraswathy College of Nursing, Karode, Thiruvananthapuram, Kerala, India. 


\section{ARTICLES}

\section{INTRODUCTION}

A minute of tension may cause a life time agony to you. Over the past two decades there has been a growing belief that the experience of stress at work has undesirable effects, both on the health and safety of workers and on the health and effectiveness of their organisation. Nursing is by its very nature a stressful profession. "Every day the nurse confronts stark suffering, grief and death as few other people do. Many nursing tasks are mundane and unrewarding. Many are, by normal standards, distasteful and disgusting. Others are often degrading; some are simply frightening," Hingley, (1984).

In times of stress, an individual normally engages in certain coping strategies to handle the stressful situations and their associated emotions. The more an individual adopts adaptive coping strategies, the less his/ her stress and better his/ her mental health. For example, Havlovic and Keenan (1995) found that employees in business fields most frequently utilised direct action coping to handle job difficulties. Therefore, the researcher has documented that the stress level is higher among nursing personnel. However, the perception of stress among nurses differs and how well they do cope with these stresses at the high risk areas, led the researcher to do this study. So this study will attempt to identify, whether or not, there is a difference in level of stress and coping effects of nurses enrolled in ICUs, emergency department and other wards such as C.T, oncology.

\section{STATEMENT OF THE PROBLEM}

'Study to assess the level of stress and coping among nurses working at high risk areas of selected C.S.I Hospitals of Kanyakumari District'

\section{OBJECTIVES OF THE STUDY}

1. To assess the level of stress among nurses working at high risk areas. To assess the level of coping among nurses working at high risk areas.

2. To find out the relationship between level of stress and coping among nurses working at high risk areas. To associate the stress and coping with selected demographic variables.

\section{MATERIALS AND METHODS}

Stress: Stress is a condition or feeling experienced when a person perceives that demand exceeds the personal and social resources of the individual to mobilise.

Coping: It is the ability of the person to adapt to the stressful situation.

High risk area: It is the area in which the registered nurse needs to deliver a heavy work load to render comprehensive care to critically ill patients with life threatening emergencies such as those chronically ill and nearing death. In this study high risk areas are ICU, emergency department and other such wards (OT and oncology).

Selected hospital: The Mission hospitals that function under the control of Kanyakumari C.S.I. diocese, Nagercoil (Neyyoor, Kulasekharam, Marthandam, and Nagercoil).

\section{ASSUMPTION}

It was assumed that nurses working at high risk areas undergo high level of stress and coping.

\section{DELIMITATION}

The study was limited to -

- Only registered nurses working in Kanyakumari Medical Mission C.S.I hospitals.

- Nurses working in ICU, emergency unit, other wards (OT, oncology) of Kanyakumari Medical Mission, C.S.I hospitals

- Nurses who were willing to participate and co-operate for the study 


\section{ARTICLES}

\section{PROJECTED OUTCOME}

The study was to find out the stress and coping of nursing personnel working at high risk areas of Kanyakumari Medical Mission, C.G.I. hospitals.

The study was to prepare the nursing personnel to have better coping responses to stressful situations.

\section{CONCEPTUAL FRAME}

The investigator adapted the Neuman (1995) systems model for this study. The intent of the Neuman Systems Model or conceptual frame work is to set forth a structure that would interpret the stress and the coping effect of nurses working at high risk areas.

The investigator aimed to identify or conclude, whether nurses are adapting to the stressful situations.

Stressors: The stressors are classified as Intra-, Inter- and extra-personal stressors.

Intra-personal stressors: These factors are capable of producing system instability or affect relationship with coworkers, physician in charge and other health Professionals working in intensive care units, emergency units and other wards (OT, oncology). e.g. conflict with physician, suffering client, criticism, working through breaks, lack of support.

Extra-personal factors: These include nursing work load, social responsibilities, exposure to health hazards, non nursing tasks, lack of rewards and stress in family.

System: The nurse is considered an open system that interacts with her work environment. The person has a core consisting of basic structure that comprises the factors or energy resources necessary for client's survival. The lines surround the basic structure.

Line of resistance: If the line of resistance is effective in their responses, the system can reconstitute. If the line of resistance is not effective, the resulting energy depletion may lead to death.

Normal line of defence: The normal line of defence has changed over times as a result of a variety of stressors.

Flexible line of defence: The flexible line of defence was able to protect the normal line of defence and act as a buffer for the client's systems in usual stable state. It is dynamic other than stable and can be altered over a short period by factors i.e. either single or multiple stressors.

Reaction to stress: The reaction to stress may be positive or negative, The nurse is in a situational crisis, utilise the coping mechanism which is further divided into positive coping (includes high and moderate coping) and negative coping (including the low coping) positive coping mechanism here means the individual is able to cope with the present situational crisis Negative coping mechanism means that the individual is unable to cope with the present situational crisis.

Prevention: Primary prevention as intervention is used to retain, attain and maintain system balance. It occurs before the system reacts to stressors which include health assessment, health promotion and maintenance of wellness.

\section{SIGNIFICANT FINDINGS}

Majority of nurses 34 (42.5\%) were in the age group of $26-35$ yrs. Nurses having $<5$ years of experience were found to be in majority $23(28.75 \%)$. 52 of the staff nurses were married. Majority, $52.5 \%$ (42) of nurses were found to be severely stressed. $40 \%$ (32) nurses were found to be moderately stressed. Only $3.75 \%$ (3) nurses were having effective coping skills.

Majority 60\% (18) of nurses in emergency department were severely stressed and $40 \%$ (12) were moderately stressed. Majority of 50\% (15) of nurses in ICU were having severe stress and $40 \%$ (12) were found having moderate stress. $10 \%$ of emergency department nurses were having effective coping skills. The association among stress and selected demographic variables like age, year of experience, type of wards and marital status were found to be significant with $=18.70 ; 20.23 ; 11.27 ; 10.04$ respectively at $(p<0.05)$ level. 


\section{ARTICLES}

The association among coping and selected demographic variables like age, year of experience and marital status were found to be significant with $=14.55 ; 15.54 ; 6.54$ respectively at $(p<0.05)$ level.

\section{CONCLUSION}

Nurses in emergency, ICU and other wards have moderate to severe level of stress. Nurses reported low to moderate level of stress at high risk areas. There was a significant relationship found between work related stress and age, year of experience, marital status and the type of ward. There exists a significant relationship between coping and age, year of experience and marital status. Therefore steps need to be taken to address stress among nurses.

\section{REFERENCE}

1. Anderson, M. \& Douglas, D. (2002) Mosby's Medical and Surgical Nursing \&Allied issues. 6ål edition, St. louis, Mosby's publications, 449, 589, 1639.

2. Asad, N. (2006) Occupational stress and job satisfaction among Nurses et a tertiary care hospital. West Indian Medical Journal, January 281 55, 10-11

3. Best, J. \& Kahn, J.(1199) Research in Education practice. New Delhi: Hall of India Pvt. Ltd, 156-157.

4. Bienestar (2006). Mental wellbeing of doctors and nurses in two hospitals in Kingston, west Indian Medical Journal, February 20, 55. 8-9.

5. Brenda. D\& Suzanne (2006) Burner and Suddarth's textbook of Medical and Surgical Nursing, Philadelphia, Lippincott publications, 8th edition 56-63.

6. Pilot. F \& Denise. B (2002) Nursing research principles methods. JB Lippincott company, Philadelphia: 227 - 231

7. Rita, S. (2002) Israeli nurses cope with multi casually terror. Journal of issues in Nursing, 7, 13.

8. Sofia. B (2003) Stress caused by emotional conditions - affect us, Journal on Nursing Administration: 25 - 28. 